\title{
Comparison of the purity and vitality of natural killer cells with different isolation kits
}

\author{
GUANGCHUAN WANG ${ }^{1,2}$, GUANG YU ${ }^{2}$, DONGMEI WANG ${ }^{1}$, SHENGNAN GUO $^{1}$ and FENGPING SHAN ${ }^{1}$ \\ ${ }^{1}$ Department of Immunology, School of Basic Medical Science, China Medical University, \\ Shenyang, Liaoning 110122; ${ }^{2}$ Department of Immunology, School of Basic Medical Science, \\ Jinzhou Medical University, Jinzhou, Liaoning 121000, P.R. China
}

Received December 8, 2015; Accepted December 23, 2016

DOI: $10.3892 /$ etm.2017.4189

\begin{abstract}
Natural killer (NK) cells are innate lymphocytes that aid in the protection of the host from infectious diseases and cancer. In vitro studies of NK cells have provided a foundation for developing clinical adoptive NK-cell transferred immunotherapy against human tumors. To elucidate the functions and mechanisms of NK cell populations, it is important to develop an optimal, highly reproducible and reliable isolation method. The present comparative study was performed with four different NK cell isolation kits of magnetic bead labeling made by Miltenyi and Stemcell companies, including positive selection kits [cluster of differentiation (CD)-49b, using the monoclonal antibody DX5) MicroBeads] and negative selection kits. In addition, the viability of NK cells isinterleukin-2 (IL-2)-dependent in vitro and thus the concentration of IL-2 is critical for maintaining longer cell viability of NK cells. NK cell purity and viability after culturing, for 24,48 or $72 \mathrm{~h}$, with or without IL-2 $(0,100,300$ or $500 \mathrm{U} / \mathrm{ml})$ was investigated in the present study. Purity of NK cells varied depending on the purification kit used, despite the same method being applied. Furthermore, more granulocytes were present in purified NK cells using Miltenyi sorting kits, particularly when using the negative selection kit. The main disadvantage of DX5-positive selection using the Stemcell and Miltenyi kits was that a high percentage of $\mathrm{CD} 3 \varepsilon^{+}$cells were mixed into the isolated NK cells. Additionally, a significant difference of NK cell purity $(\mathrm{P}=0.003)$ was observed while purification was performed
\end{abstract}

Correspondence to: Professor Fengping Shan, Department of Immunology, School of Basic Medical Science, China Medical University, 77 Puhe Road, Shenyang North New Area, Shenyang, Liaoning 110122, P.R. China

E-mail: fpshan@mail.cmu.edu.cn

Abbreviations: FCM, flow cytometry; MACS, magnetic activated cell sorting; NK cells, natural killer cells; NKT cells, natural killer T cells; IL-2, interleukin 2

Key words: natural killer cells, natural killer cell isolation, natural killer cell culture, magnetic-activated cell sorting, DX5, interleukin-2 using different surface markers. As a consequence, the use of the positive selection kit was modified and subsequently a significantly higher purity $(\mathrm{P}=0.002)$ and yield $(\mathrm{P}=0.004)$ of NK cells was obtained. Moreover, the purity of NK cells and viability with or without a range of concentrations of IL-2 was compared. Results indicated that with a higher IL-2 concentration, the NK cell purity and viability were significantly higher $(\mathrm{P}<0.05)$. To our knowledge, this is the first report that has compared the disadvantages of four commercial NK cell isolation kits from two well-known companies, and identified the effect of NK cell purity and viability, using different concentrations of IL-2. To conclude, the results of the present study are fundamental in aiding the further development of NK cell therapy protocols for murine in vivo models.

\section{Introduction}

Natural killer (NK) cells are innate immune cells whose function is critical in the first-line of defense against different types of pathogens, including viruses, bacteria and fungi $(1,2)$. Furthermore, NK cells are associated with immune surveillance against tumors, hinder the dissemination of metastatic tumors, and perform essential functions in regulating autoimmune diseases $(3,4)$. Unlike T and Blymphocytes, NK cells are constitutively able to kill target cells without prior sensitization; additionally, NK cells exhibit a variety of activating and inhibitory receptors that allow for activation and inhibition signaling, which may determine the cytotoxicity of NK cells (5).

NK cells are present in all lymphoid organs and mature NK cells may be detected in the liver, peripheral blood and spleen (6). NK1.1 has been used to distinguish NK cells in specific murine strains, including C57B1/6 (7). Cluster of differentiation (CD)-49b may associate with DX5 antibody and is also a well-known NK cell marker in different mouse strains, uch as BALB/c (8). The isolation of purified and newly separated NK cells poses a challenge as NK cells only constitute $2.5 \%$ of mouse splenocytes (9).

Previous studies have determined multiple approaches for purifying splenic NK, such as the methods of NK cell isolation proposed by Ravnik et al (10) and Patel and Linna (11), which were based on the differentiation of cells via density gradient centrifugation with continuous or discontinuous percoll 
gradients. However, flow cytometry has indicated that $<40 \%$ of density-separated cells were $\mathrm{NK} 1.1^{+} \mathrm{CD} 3 \varepsilon^{-}$, particularly from spleens of C57BL/6 mice $(10,11)$. Advancement in technology has allowed for the development of the novel method, magnetic-activated cell sorting (MACS). MACS sorting is a popular method applied in areas concerning immunology, cancer research, neuroscience, and stem cell research. Through this approach, cells are positively or negatively separated, depending on specific antigens present (12). For NK cell sorting, positive selection may be gaged by selecting antibodies against NKp46 or CD49b (DX5) and negative selection may be achieved for naïve NK cell purification using commercially available kits.

Different conclusions and several problems have been identified in the purification of murine NK cells as the result of using different commercial kits (13). For that reason, an extensive comparative study of four different NK cells isolation kits based on MACS separation in C57Bl/6 mice was performed in the present study. The present study recognized that NK cells are short-lived and IL-2-dependent in vitro. Thus, the concentration of IL-2 was an important factor to consider when evaluating the effects of various drugs on $\mathrm{NK}$ cells. Consequently, the approach of the present study required freshly isolated NK cells and evaluated the purity and viability of NK cells in the absence or presence of different concentration of IL-2 for 24,48 or $72 \mathrm{~h}$.

\section{Materials and methods}

Animals. A total of 30 female 6-8-week-old C57BL/6 mice weighing 18-20 g were obtained from Harlan Slac Laboratory Animals Co., Ltd. (Shanghai, China). Mice were maintained at China Medical University in a pathogen-free animal house. Mice were housed in a temperature $\left(21 \pm 1^{\circ} \mathrm{C}\right)$, humidity $(55 \pm 10 \%)$, and 12-h light/dark cycle controlled room. Food and water were available ad libitum. All experiments with animals were performed in accordance with the Guide for the Care and Use of Laboratory Animals as approved by the China National Institutes of Health.

Cell culture. Freshly isolated NK cells using the Stemcell Mouse NK Cell Isolation kit (catalogue no. 19855; STEMCELL Technologies, Inc., Cambridge, UK) were cultured in Roswell Park Memorial Institute-1640 medium (Biological Industries, Kibbutz Beit-Haemek, Israel) supplemented with $10 \%$ fetal bovine serum (FBS; Biological Industries), $2 \mathrm{mM}$ L-glutamine (Lonza, Shanghai, China), $50 \mu \mathrm{M}$ $\beta$-mercapto ethanol (Sigma-Aldrich; Merck Millipore, Darmstadt, Germany) and antibiotics (100 U/ml penicillin, $100 \mu \mathrm{g} / \mathrm{ml}$ streptomycin and $100 \mu \mathrm{g} / \mathrm{ml}$ kanamycin) (HyClone; GE Healthcare Life Sciences, Logan, UT, USA) at a density of $5 \times 10^{5}$ cells $/ \mathrm{ml}$ in 96 -well flat plates. NK cells were cultured for 24,48 or $72 \mathrm{~h}$ in the absence or presence of IL-2 (PeproTech, Inc., Rocky Hill, NJ, USA). At the designated time points, NK cells were assessed for viability and surface phenotype using flow cytometry (FCM). Cells were maintained in a humidified atmosphere containing $5 \% \mathrm{CO}_{2}$ and $95 \%$ air at $37^{\circ} \mathrm{C}$.

Sample preparation for magnetic activated cell sorting (MACS). Mice were anesthetized by intraperitoneal injection of Inactin (thiobutabarbital, 100 mg/kg; Sigma-Aldrich; Merck Millipore) and sacrificed by cervical dislocation, and spleens were removed by mechanical dissociation and placed on a petri dish containing pre-cooled phosphate-buffered saline (PBS) supplemented with $2 \%$ FBS as described previously (12). Spleens were mashed using a moisturized cell strainer (70- $\mu \mathrm{m}$ nylon mesh) using a plunger and a cell strainer positioned above a 50-ml conical tube was used to transfer the single cell suspension through the strainer into the tube. The petri dish and the strainer were rinsed with pre-cooled PBS supplemented with 2\% FBS. Erythrocytes were lysed with ammonium chloride potassium lysing buffer. Subsequently, murine splenocytes were transferred through another $70-\mu \mathrm{m}$ cell strainer into a new 50-ml conical tube. Cell numbers were counted by trypan blue exclusion. Following the different cell isolation procedures, NK cell fractions were harvested, visualized under a light microscope and the number of cells counted on a hemocytometer using trypan blue (the percentage of viable cells=total cells-blue cells/total cells). Subsequently, FCM analysis was performed (as described in Flow cytometry) to determine the percentage of NK cells (the percentage of NK cells=all cells at lymphocyte locations/total cells) vs. contaminating lymphocytes (the percentage of contaminating lymphocytes $=$ all cells at granulocyte locations/total cells) using BD FACS DIVA version 6.0 software (BD Biosciences, San Jose, CA, USA).

Miltenyi NK Cell Isolation Kit II. The NK Cell Isolation kit II was used according to the manufacturer's instructions (130-096-892) by using an LS column on the Midi MACS separator (both Miltenyi Biotec GmbH, Bergisch Gladbach, Germany). Splenocyte suspensions $\left(1 \times 10^{8}\right.$ cells $\left./ \mathrm{ml}\right)$ were centrifuged at $300 \mathrm{x} g$ for $10 \mathrm{~min}$ at $4^{\circ} \mathrm{C}$ and resuspended in $400 \mu \mathrm{l}$ isolation buffer (containing PBS, pH 7.2, $0.5 \%$ bovine serum albumin and $2 \mathrm{mM}$ ethylenediaminetetraacetic acid). Subsequently, $100 \mu 1 \mathrm{NK}$ cell biotin-antibody mixture was added, and the mixture was incubated for $5 \mathrm{~min}$ in the refrigerator $\left(2-8^{\circ} \mathrm{C}\right)$. Following washing with isolation buffer, splenocytes were resuspended in $800 \mu$ l isolation buffer. Subsequently, $200 \mu \mathrm{l}$ anti-biotin microbeads were added and cells were incubated for an additional $10 \mathrm{~min}$ in the refrigerator $\left(2-8^{\circ} \mathrm{C}\right)$. During the incubation period, the LS column was prepared by rinsing with $3 \mathrm{ml}$ of isolation buffer. Cell suspensions were loaded onto the column and the flow-through containing unlabeled cells was collected, representing the enriched NK cells. To obtain more NK cells, the column was subsequently washed with $3 \mathrm{ml}$ isolation buffer again and the flow-through cells were collected.

Miltenyi CD49b (DX5) positive selection kit. CD49b (DX5) microbeads were used according to the manufacturer's instructions (130-052-501) using an MS Column on the MiniMACS separator (Miltenyi Biotec, GmbH). Splenocyte suspensions at a density of $1 \times 10^{8} \mathrm{cell} / \mathrm{ml}$ were centrifuged at $300 \mathrm{x} \mathrm{g}$ for $10 \mathrm{~min}$ at $4^{\circ} \mathrm{C}$ and resuspended in $900 \mu \mathrm{l}$ isolation buffer. A total of $100 \mu \mathrm{l} \mathrm{CD} 49 \mathrm{~b}$ (DX5) microbeads were added and cells were incubated for $15 \mathrm{~min}$ at $4-8^{\circ} \mathrm{C}$. Following washing with isolation buffer, splenocytes were resuspended in $500 \mu \mathrm{l}$ isolation buffer and the MS column was prepared by rinsing with $500 \mu 1$ isolation buffer. The cell suspension was applied onto 
Table I. Purity and viability of NK cells with different concentration of IL-2.

\begin{tabular}{|c|c|c|c|c|c|c|}
\hline \multirow{2}{*}{$\begin{array}{l}\text { IL-2 } \\
\text { concentration, } \mathrm{U} / \mathrm{ml}\end{array}$} & \multicolumn{3}{|c|}{ NK cells purity of living cell, $\%$} & \multicolumn{3}{|c|}{ Viable cell/total cell, $\%$} \\
\hline & $24 \mathrm{~h}$ & $48 \mathrm{~h}$ & $72 \mathrm{~h}$ & $24 \mathrm{~h}$ & $48 \mathrm{~h}$ & $72 \mathrm{~h}$ \\
\hline 0 & $72.57 \pm 4.30$ & $53.37 \pm 5.44$ & $22.13 \pm 3.67$ & $21.10 \pm 4.78$ & $9.23 \pm 1.93$ & $7.50 \pm 1.05$ \\
\hline 100 & $83.70 \pm 5.16^{\mathrm{a}}$ & $81.83 \pm 3.95^{\mathrm{a}}$ & $82.17 \pm 3.50^{\mathrm{a}}$ & $45.77 \pm 5.34^{\mathrm{a}}$ & $29.13 \pm 3.39^{\mathrm{a}}$ & $32.17 \pm 3.15^{\mathrm{a}}$ \\
\hline 300 & $94.07 \pm 2.51^{\mathrm{a}, \mathrm{b}}$ & $90.83 \pm 3.03^{\mathrm{a}, \mathrm{b}}$ & $92.73 \pm 2.30^{\mathrm{a}, \mathrm{b}}$ & $71.30 \pm 3.29^{\mathrm{a}, \mathrm{b}}$ & $43.50 \pm 3.24^{\mathrm{a}, \mathrm{b}}$ & $52.23 \pm 3.70^{\mathrm{a}, \mathrm{b}}$ \\
\hline 500 & $95.20 \pm 1.49^{\mathrm{a}, \mathrm{b}}$ & $95.97 \pm 1.55^{\mathrm{a}, \mathrm{b}}$ & $95.63 \pm 1.14^{\mathrm{a}, \mathrm{b}}$ & $74.60 \pm 2.02^{\mathrm{a}, \mathrm{b}}$ & $71.90 \pm 1.25^{\mathrm{a}-\mathrm{c}}$ & $72.30 \pm 2.10^{\mathrm{a}-\mathrm{c}}$ \\
\hline
\end{tabular}

Values are expressed as mean \pm standard deviation. NK, natural killer; IL-2, interleukin-2; ${ }^{\mathrm{P}}<0.05$ vs. the group treated with $0 \mathrm{U} / \mathrm{ml}$ of IL-2; ${ }^{\mathrm{b}} \mathrm{P}<0.05$ vs. the group treated with $100 \mathrm{U} / \mathrm{ml}$ of IL-2; ${ }^{\mathrm{C}}<0.05$ vs. the group treated with $300 \mathrm{U} / \mathrm{ml}$ of IL-2.

the column and cells were washed with isolation buffer three times. Subsequently, the column was removed from the separator and placed on a $15 \mathrm{ml}$ conical tube. A total of $1 \mathrm{ml}$ buffer was pipetted onto the column and the fraction was immediately flushed out using magnetically labeled cells by firmly applying the plunger supplied with the column, providing the purified $\mathrm{CD} 49 \mathrm{~b}^{+}$cells.

Stemcell CD49b Positive Selection kit. The Mouse CD49b Positive Selection kit was performed according to the manufacturer's instructions (18755; Stemcell Technologies UK Ltd., Cambridge, UK) using Falcon 5-ml polystyrene round-bottom tubes (352058; BD Biosciences) on a purple EasySep magnet (18000; Stemcell Technologies UK Ltd.). Splenocyte suspensions $\left(1 \times 10^{8}\right.$ cells $\left./ \mathrm{ml}\right)$ were centrifuged at $300 \times \mathrm{g}$ for $10 \mathrm{~min}$ at $4^{\circ} \mathrm{C}$ and resuspended in $1 \mathrm{ml}$ sorting buffer (PBS and $2 \%$ FBS with $1 \mathrm{mM}$ ethylenediaminetetraacetic acid) in a $5 \mathrm{ml}$ (12x75 mm) polystyrene tube. Subsequently, $50 \mu 1$ EasySep mouse CD49b phycoerythrin (PE) labeling reagent was added, and the suspension was incubated at room temperature $\left(15-25^{\circ} \mathrm{C}\right)$ for $15 \mathrm{~min}$. A total of $100 \mu 1$ EasySep PE selection cocktail was added and the cells were incubated at room temperature for $15 \mathrm{~min}$. Subsequently, $50 \mu 1$ nanoparticles were added and the cells were incubated at room temperature for $10 \mathrm{~min}$. Finally, the cell suspensions were made to a total volume of $2.5 \mathrm{ml}$ by adding the recommended medium, and were placed into the magnet for $5 \mathrm{~min}$. The supernatant fraction was poured off three times following 5 min separations in the magnet. Magnetically-labeled cells (positively selected cells) remained inside the tube; the tube was removed from the magnet and cells were resuspended in $1 \mathrm{ml}$ desired medium.

Stemcell Mouse NK Cell Isolation kit. The Mouse NK Cell Isolation kit was used according to the manufacturer's instructions (19855; Stemcell Technologies UK Ltd.) using Falcon 5-ml polystyrene round-bottom tubes on the EasySep magnet. Splenocyte suspensions at a density of $1 \times 10^{8}$ cells $/ \mathrm{ml}$ were centrifuged at $300 \times \mathrm{g}$ for $10 \mathrm{~min}$ at $4^{\circ} \mathrm{C}$ and resuspended in $1 \mathrm{ml}$ of recommended medium in a $5-\mathrm{ml}$ polystyrene tube. A total of $50 \mu \mathrm{l}$ EasySep mouse NK cell isolation cocktail was added, and cells were incubated at room temperature $\left(15-25^{\circ} \mathrm{C}\right)$ for $10 \mathrm{~min}$. Subsequently, $100 \mu \mathrm{l}$ EasySep Streptavidin RapidSpheres 50002 was added, and cells were incubated at room temperature $\left(15-25^{\circ} \mathrm{C}\right)$ for $5 \mathrm{~min}$. Cell suspensions were brought up to a total volume of $2.5 \mathrm{ml}$ by adding the recommended medium, and were placed into the magnet for $5 \mathrm{~min}$ at room temperature $\left(15-25^{\circ} \mathrm{C}\right)$. The EasySep magnet was removed and the desired fraction was poured off into a $15-\mathrm{ml}$ tube three times following $5 \mathrm{~min}$ separations in the magnet. The isolated cells in the $15-\mathrm{ml}$ tube were naïve NK cells.

Modified NK cell isolation. To obtain high purity NK cells, the Miltenyi CD3e MicroBead kit (130-094-973) was used in combination with a Miltenyi CD49b (DX5) positive selection kit. Splenocytes were labeled with CD3e-biotin and the cells were magnetically labeled with anti-biotin micro beads. Cell suspensions were loaded onto the MACS column, which was placed in the magnetic field of a MACS separator. Magnetically labeled $\mathrm{CD} 3 \varepsilon^{+}$cells were retained within the column, while the unlabeled cells ran through. This cell fraction was depleted of CD3 $\varepsilon^{+}$cells. Subsequently, the CD49b (DX5) micro beads were used according to the manufacturer's instructions to isolate NK cells from the cell fraction depleted of $\mathrm{CD} 3 \varepsilon^{+}$cells.

Flow cytometry. Anti-mouse antibodies used for flow cytometry were as follows: PE-conjugated anti-NK1.1 (PK136; catalogue no. 108707; 1:100), allophycocyanin-conjugated anti-NK1.1 (PK136; catalogue no. 108709; 1:100), Fluorescein isothiocyanate-conjugated anti-CD3e (145-2C11; catalogue no. 100305; 1:100), PE-conjugated anti-F4/80 (BM8; catalogue no. 123109; 1:100), PE-conjugated anti-CD8a (53-6.7; catalogue no. $100707 ; 1: 100)$, peridininchlorophyll protein complex-CY5.5-conjugated anti-CD4 (GK1.5; catalogue no. 100434; 1:100) (BioLegend, Inc., San Diego, CA, USA). Cell viability was confirmed by staining the cells with 7-aminoactinomycin D (420404; 1:100; BioLegend, Inc.). NK cell purity was evaluated using flow cytometry as described previously (12). Briefly, freshly isolated NK cells or cultured NK cells were collected and washed in PBS twice. Then cells were resuspended in $100 \mu \mathrm{l}$ staining buffer (421002; BioLegend, Inc.) and incubated on ice for $15 \mathrm{~min}$ with combination of PE-conjugated anti-NK1.1 or APC-conjugated anti-NK1.1 and FITC-conjugated anti-CD3e antibodies. After extensive washing with PBS, cells were resuspended in $500 \mu \mathrm{l}$ PBS and $5 \mu 1$ 7-AAD was added into the suspension for $10 \mathrm{~min}$. The stained cells were then analyzed by FCM. A minimum of 10,000 events was acquired using a FACS Canto II flow 
cytometer and analyzed with BD FACS DIVA version 6.0 software (BD Biosciences).

Statistical analysis. Statistical analysis was performed using SPSS 16.0 statistical software package (SPSS, Inc., Chicago, IL, USA). Values were expressed as the mean \pm standard deviation from at least three independent experiments. Statistical significance of differences was determined by a one-way analysis of variance analysis using the Bonferroni t-test. $\mathrm{P}<0.05$ was considered to indicate a statistically significant difference.

\section{Results}

Purity of NK cells purified with Miltenyi NK Cell Isolation kit II. The proportion of NK cells was first detected in female $\mathrm{C} 57 \mathrm{Bl} / 6$ mice of identical age. For this purpose, FCM analysis of NK cells, defined as $\mathrm{NK} 1.1^{+} \mathrm{CD} 3 \varepsilon^{-}$, was performed in viable splenocytes. Results indicated that in $\mathrm{C} 57 \mathrm{Bl} / 6$ mice, the spleen contained $2.63 \pm 0.31 \%$ NK cells (Fig. 1). To confirm cell purity and the success of the isolation procedure of the Miltenyi NK Cell Isolation kit II, isolated cells were phenotyped by FCM for the expression of NK1.1 and CD3r. NK cell purity in the gated population was $81.47 \pm 3.98 \%$ (Fig. $2 \mathrm{~A}$ ); however, the percentage of the gated NK cells population based on forward and side scatter characteristics was $34.37 \pm 5.41 \%$ (Fig. 2A). There was a large population $(33.83 \pm 5.58 \%$; Fig. $2 \mathrm{~A})$ at the position of granulocytes; however, the percentage was only $1.83 \pm 0.15 \%$ in the splenocytes (Fig. 1). To identify the prosperity of this population, cells were stained with F4/80 antibody. The findings revealed that almost all of the population was F4/80 positive (Fig. 2). Isolated cells were cultured with $500 \mathrm{U} / \mathrm{ml} \mathrm{IL-2}$ for $24 \mathrm{~h}$ to deplete this population. Notably, following the subsequent depletion step, almost all cells underwent cell death and the percentages of gated NK cells and NK cell purity were increased (Fig. 2B).

Purity obtained with Miltenyi CD49b (DX5) positive selection kit. Isolated cells from the Miltenyi CD49b (DX5) positive selection kit were phenotyped by FCM for the expression of NK1.1 and CD3e. Results indicated that the NK cell purity from this kit was $\sim 51.50 \pm 4.52 \%$ (Fig. 1). However, this kit presented with certain issues. The percentage of the granulocyte population $(9.07 \pm 1.19 \%)$ was significantly increased when compared with that in the normal splenocytes $(1.83 \pm 0.15 \%$; $\mathrm{P}=0.005)$. Furthermore, the percentage of natural killer $\mathrm{T}(\mathrm{NKT})$ cells, defined as the NK $1.1^{+} \mathrm{CD} 3 \varepsilon^{+}(10.8 \pm 1.49 \%)$ population, was increased in the isolated viable lymphocyte population when compared with the splenocytes $(1.13 \pm 0.25 \%)$, which were also contaminated with numerous CD $3 \varepsilon^{+}$NK1.1 cells $(32.97 \pm 4.17 \%$; Fig. 1$)$.

Purity of Stemcell CD49b Positive Selection kit. Since the positively selected cells of the Stemcell CD49b Positive Selection kit were already PE-labeled, the purity was assessed directly by FCM. Anticipated results were achieved using the recommended marker in this kit and the CD49b+ (DX5) cell content of selected cells was $92.90 \pm 2.36 \%$ (Fig. 3). To confirm NK cell purity, cells were phenotyped by FCM for the expression of NK1.1 and CD3r, following purification.
Surprisingly, the NK cell purity was only $64.93 \pm 2.62 \%$ and the gated cell population was also slightly contaminated with NKT cells $(6.60 \pm 1.21 \%)$. Furthermore, purified cells were analyzed using another NK cell marker, CD $49 b^{+} \mathrm{CD} 3 \varepsilon^{-}$. The percentage of $\mathrm{CD} 49 \mathrm{~b}^{+} \mathrm{CD} 3 \varepsilon^{-}$cell population was $79.40 \pm 2.95 \%$ and the $\mathrm{CD} 49 \mathrm{~b}^{+}$cells included a large population of $\mathrm{CD} 3 \varepsilon^{+}$

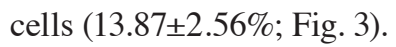

Purity of Stemcell Mouse NK Cell Isolation kit. NK cell purity as determined by the Stemcell Mouse NK Cell Isolation kit was $81.97 \pm 3.40 \%$ in the viable lymphocyte population, following purification. No contaminated cells were identified at the position of granulocytes and no NKT cell contamination was observed (Fig. 4).

Purity of modified NK cell isolation. In the present study, the Miltenyi NK cell positive selection kit (DX5 positive selection kit) was observed to be contaminated with $\mathrm{CD} 3 \varepsilon^{+}$cells. In order to deplete this population of cells, the Miltenyi CD3e MicroBead kit was used in combination with the Miltenyi CD49b (DX5) positive selection kit. The efficiency of the Miltenyi CD3 $\varepsilon$ MicroBead kit was identified, and the results indicated a high purity of $\mathrm{CD}^{+}$cells were enriched in the positive portion without granulocyte contamination. Subsequently, the results of the Miltenyi CD3e MicroBead kit were used combination with the Miltenyi CD49b (DX5) positive selection kit and showed that the NK cell purity was $73.23 \pm 2.83 \%$ and the NKT cell contamination was depleted. However, the contamination

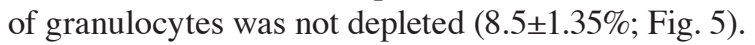

Purity and viability of NK cells in presence of different concentrations of IL-2. Freshly isolated NK cells from murine stem cells were cultured using an NK cell isolation kit at a density of $5 \times 10^{5}$ cells $/ \mathrm{ml}$ in 96 -well flat plates for 24,48 or $72 \mathrm{~h}$ in the absence or presence of IL-2 (0, 100, 300 or $500 \mathrm{U} / \mathrm{ml})$. The purity and viability of NK cells was assessed using FCM following culturing for 24,48 or $72 \mathrm{~h}$ (Fig. 6A-C) and the statistical analysis of the purity and viability were performed as presented in Fig. 6E and F. Detailed results were presented in Table I and Fig. 6. The results revealed that at higher IL-2 concentration, the NK cell purity and viability are significantly higher (Fig. 6E and F; P<0.05). The majority of NK cells under went cell death following $24 \mathrm{~h}$ in culture in absence of IL-2.

Comparison of the purity and time required of different NK cell isolation kits. The purity and time required for NK cell isolation using different kits were compared as presented in Fig. 7. Without consideration of the yield of purified NK cells, the NK cells purity and the time required of different kits are

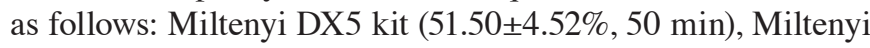
NK Cell Isolation kit II $(81.47 \pm 3.98 \%, 50 \mathrm{~min})$, modified NK cell isolation $(73.23 \pm 2.83 \%, 110 \mathrm{~min})$, Stemcell CD49b Positive Selection kit $(64.93 \pm 2.62 \%, 60 \mathrm{~min})$, Stemcell Mouse NK Cell Isolation kit $(81.97 \pm 3.40 \%, 30 \mathrm{~min})$.

\section{Discussion}

NK cells are innate lymphocytes that provide host protection against infectious diseases and cancer. In vitro studies of NK cells are necessary to obtain fundamental information on their 

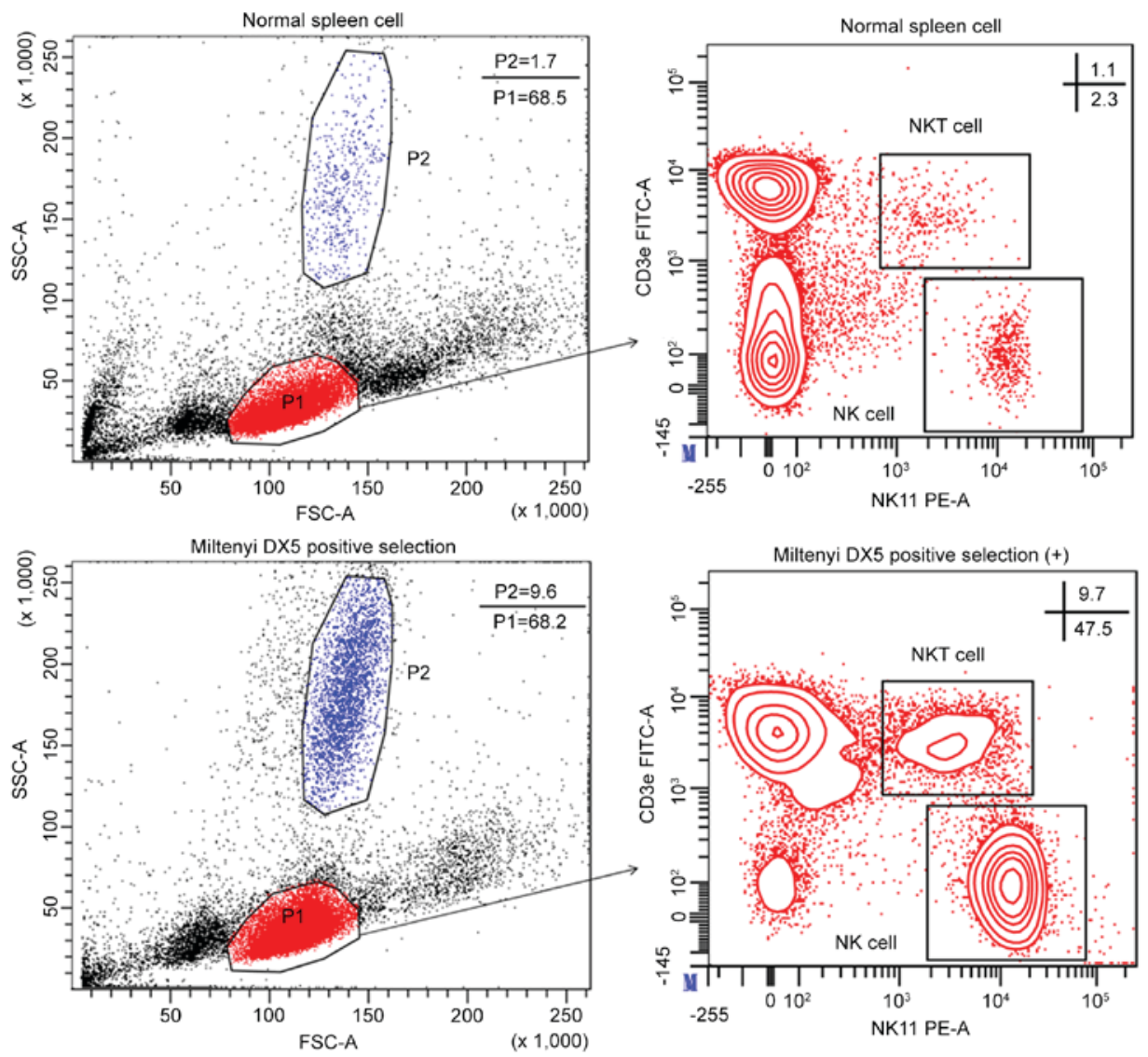

Figure 1. FCM analysis of purified splenic NK cells using a Miltenyi CD49b (DX5) positive selection kit. Purity of NK cell isolates was evaluated using FCM. The indicated percentage of contaminated granulocytes was represented as the granulocytes population (P2)/total cell population x100. NK cell purity is shown as a percentage of the total gated viable lymphocyte population. NK cells were defined as NK1.1 $1^{+} \mathrm{CD} 3 \varepsilon^{-}$. The indicated percentages represent the purity efficacy represented as the NK cell population/total viable lymphocyte population (P1) x100. The percentage of NKT cell defined as NK1.1+CD3 $\varepsilon^{+}$was also indicated. This plot is one representative experiment obtained from at least three separate assays performed in parallel. FCM, flow cytometry; NK, natural killer; FSC, forward scatter; SSC, side scatter; FITC, fluorescein isothiocyanate; PE, phycoerythrin; NKT cell, natural killer T cell.

function and the mechanisms of their interaction with other cells. Mouse models are considered useful tools in developing pre-clinical adoptive NK cell transfer immunotherapy against human tumors (14). A prerequisite for further detailed functional characterization of NK cells is how to optimize the purification method. In the present study, the purity of NK cells was identified to be varied among the different purification kits used, despite the same method being applied. More granulocytes were detected in the purified NK cells using the Miltenyi sorting kit, particularly while using the negative selection kit. The main drawback of DX5-positive selection using Stemcell and Miltenyi kits was that a high percentage of $\mathrm{CD} 3 \varepsilon^{+}$cells were mixed into the isolated NK cells. Furthermore, a significant difference in NK cell purity was observed while the purification was performed using different surface markers. Therefore, the positive selection kit procedure was modified and a higher purity and yield of NK cells was obtained. Moreover, the purity of NK cells was compared with the viability with or without a range of concentrations of IL-2. These findings revealed that the higher IL-2 concentrations resulted in a higher purity of NK cells.

The purity and time required for NK cells isolation to occur in different kits was compared. Without consideration of the time required and the yield of purified NK cells, the NK cells purity in the gated viable mononuclear cell population of negative selection was higher than that of positive selection. As for the specific kits, NK cell purity of the Stemcell kit was higher when compared with the Miltenyi kit, particularly the positive selection kit. Compared with Stemcell kits, there was a severe issue with granulocyte contamination of the purified NK cells based on forward scatter and side scatter properties when using Miltenyi sorting kits, particularly with the negative selection kit, which affected the yield of NK cells. Following FCM identification, this contaminated population was identified as almost entirely F4/80 positive. Thus, it was speculated that this population was likely macrophages. In order to deplete this population from purified NK cells, the total isolated cells were cultured for $24 \mathrm{~h}$. However, this population consisted of non-adherent cells and almost all cells underwent cell death following $24 \mathrm{~h}$ in culture. Thus, there are no macrophages in the contaminated population, thus they may be neutrophils, eosinophilic or basophile granulocytes because these cells are non-adherent and short-lived (15). The exact type of these contaminating cells requires further explanation. Additionally, the CD3e-positive selection kit and DX5-positive selection kit were combined to achieve a high purity of NK cells. When the $\mathrm{CD} 3 \varepsilon$-positive selection kit was initially used, granulocyte contamination was not identified in the positive fraction; however, after using the DX5-positive kit, the granulocytes contamination was detected again. These results confirmed 
A
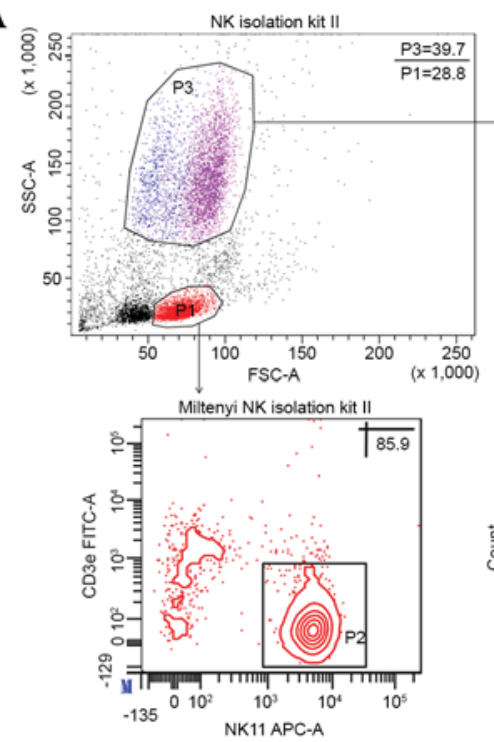
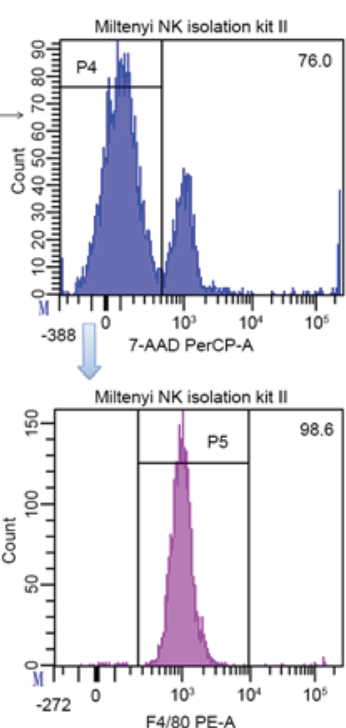

B
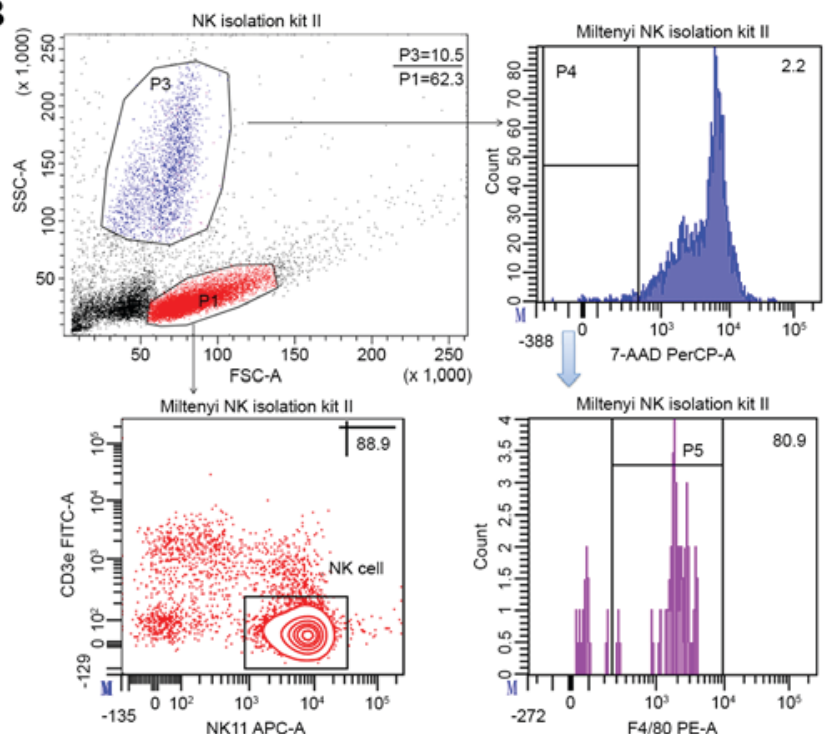

Figure 2. FCM analysis of purified splenic NK cells using a Miltenyi NK cell isolation kit II. (A) Purity of NK cell isolates were evaluated using FCM. NK cell purity is shown as a percentage of the total gated viable lymphocyte population (P1). NK cells were defined as NK1.1 ${ }^{+} \mathrm{CD} 3 \varepsilon^{*}$. The indicated percentages represent the purity efficacy represented as the NK cell population/total viable lymphocyte population (P1) x100. A large population at the position of granulocytes (P3) was identified using F4/80 antibody. (B) Purity of NK cells and the contaminated granulocytes were evaluated using FCM following culturing with $500 \mathrm{U} / \mathrm{ml}$ of IL-2 for $24 \mathrm{~h}$. This plot is one representative experiment obtained from at least three separate assays performed in parallel. FCM, flow cytometry; NK, natural killer; CD, cluster of differentiation; FSC, forward scatter; SSC, side scatter; FITC, fluorescein isothiocyanate; PE, phycoerythrin.
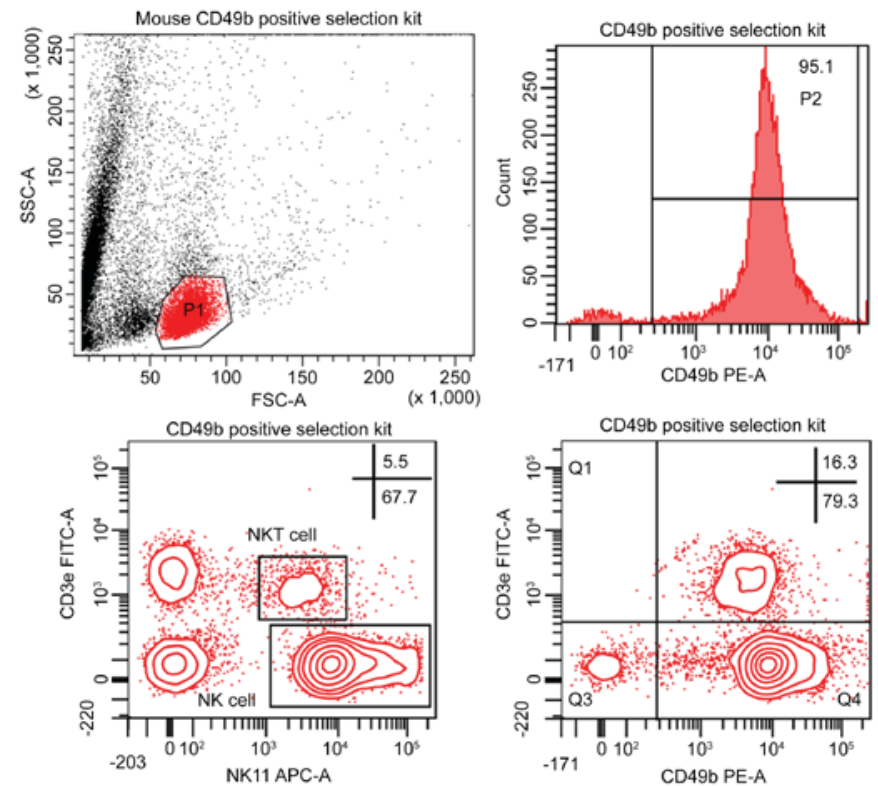

Figure 3. FCM analysis of purified splenic NK cells using a Stemcell CD49b positive selection kit. NK cell purity is shown as a percentage of the total gated viable lymphocyte population (P1). The histogram represents the percentage of CD49b cells of P1. NK cells were defined as NK1.1 ${ }^{+} \mathrm{CD} 3 \varepsilon^{-}$ or $\mathrm{CD} 49 \mathrm{~b}^{+} \mathrm{CD} 3 \varepsilon^{-}$. The indicated percentages represent the purity efficacy represented as the NK cell population/total viable lymphocyte population (P1) $\mathrm{x} 100$. The percentage of $\mathrm{NKT}$ cell, defined as $\mathrm{NK} 1.1^{+} \mathrm{CD} 3 \varepsilon^{+}$, was also indicated. This plot is one representative experiment obtained from at least three separate assays performed in parallel. FCM, flow cytometry; NK, natural killer; CD, cluster of differentiation; FSC, forward scatter; SSC, side scatter; FITC, fluorescein isothiocyanate; PE, phycoerythrin; NKT cell, natural killer T cell.

the theory that contaminated cells were reserved due to CD49b expression, although the exact type of these contaminating

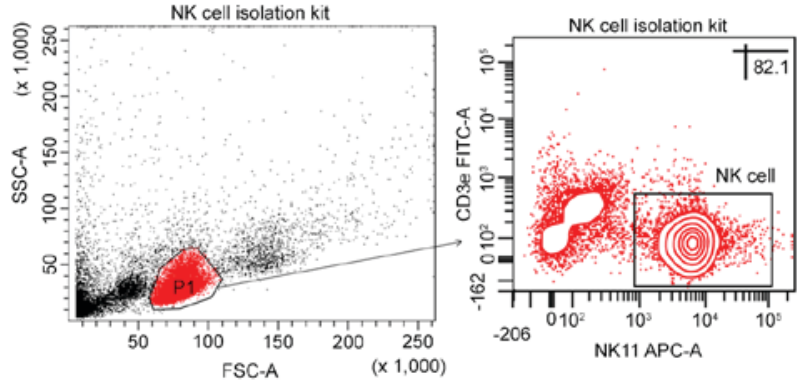

Figure 4. FCM analysis of purified splenic NK cells using a Stemcell mouse NK cell isolation kit. NK cell purity is shown as a percentage of the total gated viable lymphocyte population (P1). The indicated percentage represents the purity efficacy represented as the NK cell population/total viable lymphocyte population (P1) $\times 100$. This plot is one representative experiment obtained from at least three separate assays performed in parallel. FCM, flow cytometry; NK, natural killer; FSC, forward scatter; SSC, side scatter; FITC, fluorescein isothiocyanate; PE, phycoerythrin.

cells $\left(\mathrm{CD} 49 \mathrm{~b}^{+} \mathrm{F} 4 / 80^{+}\right)$requires further explanation. When NK cells were isolated using Miltenyi kits, the normal prepared spleen cells were not advantageous due to the enriched granulocytes observed following purification. We recommend that the spleen cells are pretreated first to deplete the granulocytes, which may be achieved by gradient centrifugation. Another disadvantage of NK cell isolation using DX5-positive selection according to both Stemcell and Miltenyi kits was that the isolates contained a high percentage of contaminating $\mathrm{CD} 3 \varepsilon^{+}$ cells, including NKT cells $\left(\mathrm{NK} 1.1^{+} \mathrm{CD} 3 \varepsilon^{+}\right)$and some $\mathrm{T}$ cells $\left(\mathrm{NK} 1.1^{-} \mathrm{CD} 3 \varepsilon^{+}\right)$. The predominant reason for this problem is in the expression of CD49b. NKT cells and certain T cells may express CD49b $(16,17)$. Thus, using CD49b as sorting target may cause these cells to be reserved in the mixture. This problem requires a solution by alternative means, such 
A

B
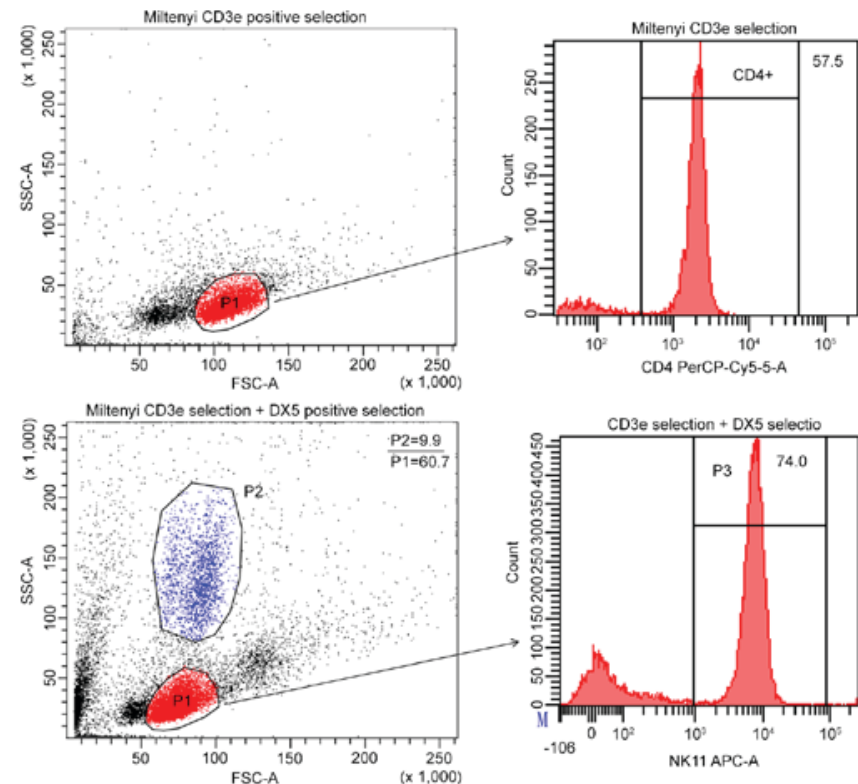
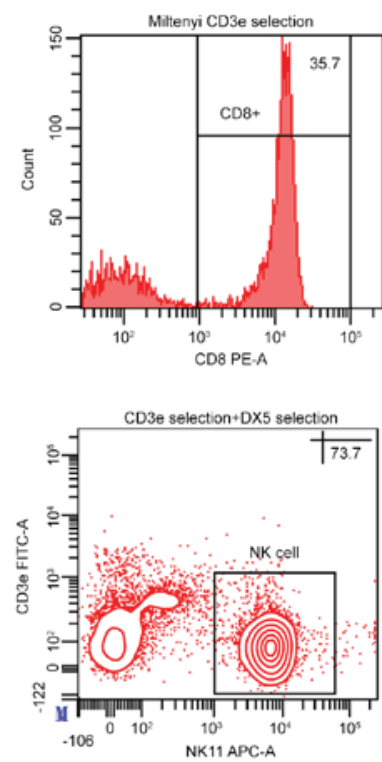

Figure 5. FCM analysis of purified splenic NK cells using a modified NK cell isolation protocol. (A) Results from using the Miltenyi CD3e MicroBead kit. $\mathrm{CD}^{+}$and $\mathrm{CD}^{+}$cell purity is shown as a percentage of the total gated viable lymphocyte population (P1). The indicated histogram percentages represent the purity efficacy represented as the $\mathrm{CD}^{+}$or $\mathrm{CD} 8^{+}$cell population/total viable lymphocyte population (P1) x100. (B) Results of using the Miltenyi CD3e MicroBead kit in combination with the Miltenyi CD49b (DX5) positive selection kit. The indicated percentage of contaminated granulocytes represented as the granulocytes population (P2)/total cell population x100. NK cell purity is shown as a percentage of the total gated viable lymphocyte population (P1). The indicated histogram percentages represent the NK1.1 ${ }^{+}$cell population/total viable lymphocyte population (P1) x100. FCM, flow cytometry; NK, natural killer; $\mathrm{CD}$, cluster of differentiation; FSC, forward scatter; SSC, side scatter; FITC, fluorescein isothiocyanate; PE, phycoerythrin.

A
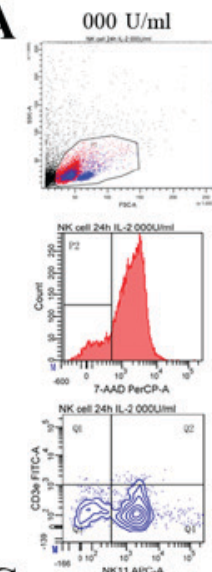

C
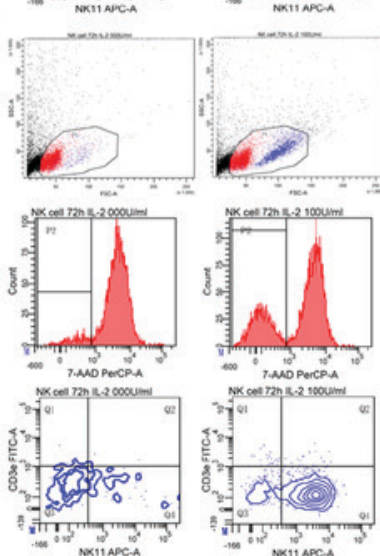
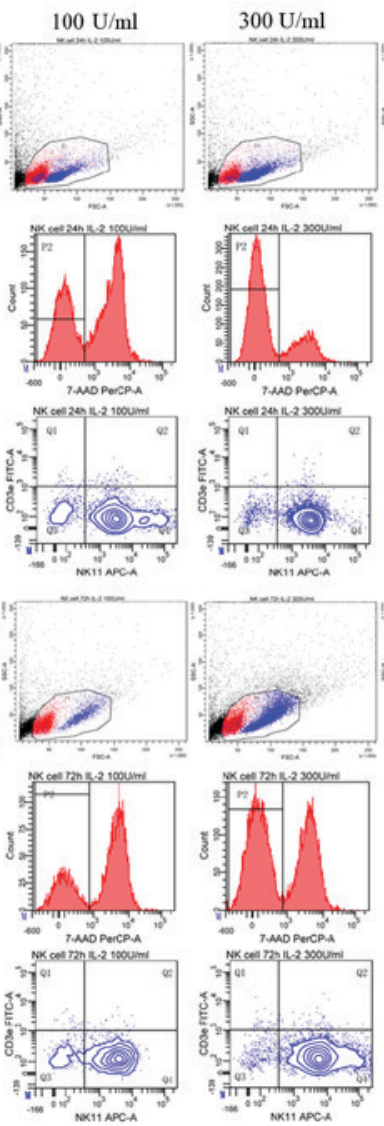
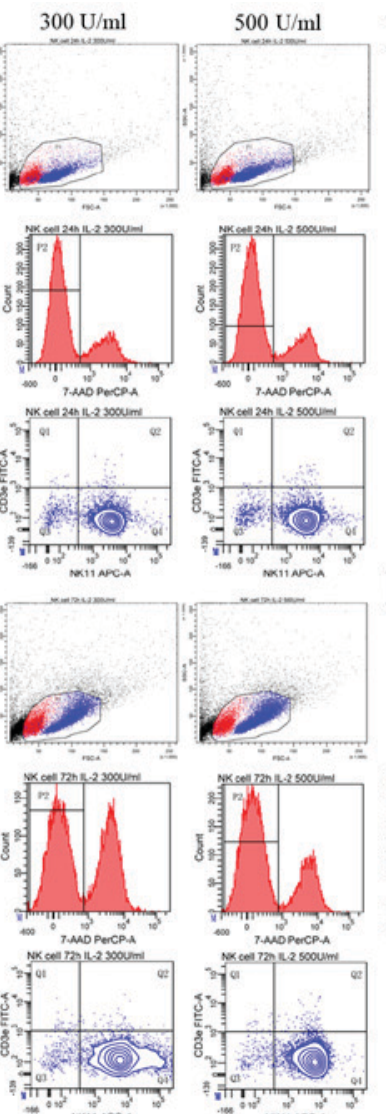

B
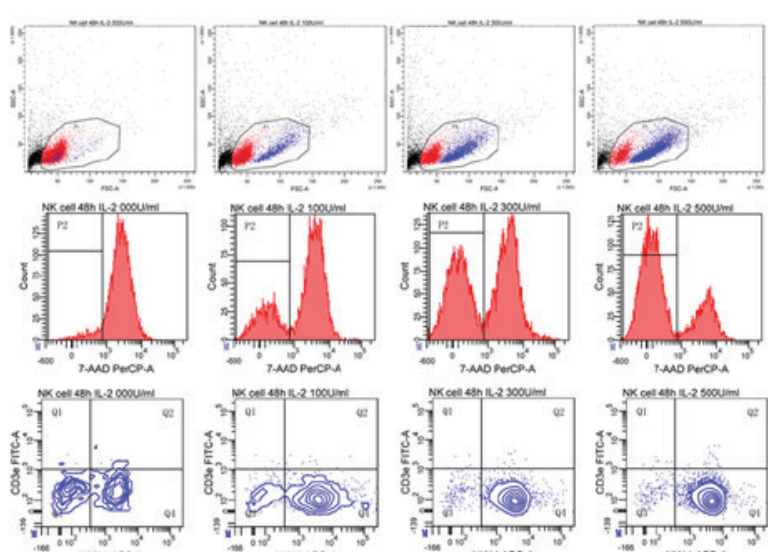

D
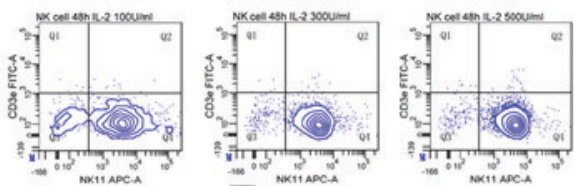

$\mathbf{E}$
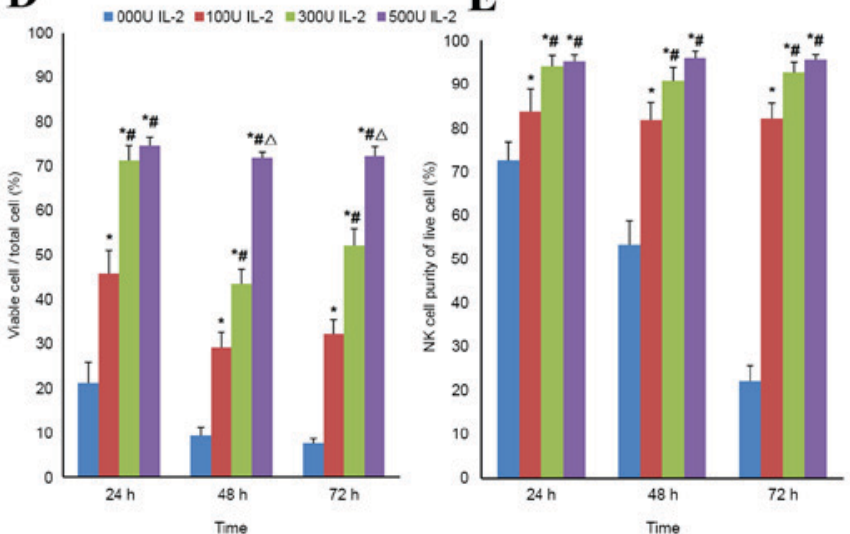

Figure 6. Analysis of the purity and viability of NK cells in the presence of different concentrations of IL-2 by FCM. Purity and viability of NK cell were evaluated using FCM following culturing for (A) 24, (B) 48 or (C) 72 h. All cells, except debris, were gated based on FSC and SSC. Subsequently, 7-AAD was used to identify the percentage of viable cells. NK cell purity was assessed in viable cells using NK1.1 $1^{+} \mathrm{CD} 3 \varepsilon^{-}$. (D) Viability and (E) purity of NK cells following culturing for 24,48 , and $72 \mathrm{~h}$. Data are expressed as mean \pm standard deviation. ${ }^{~} \mathrm{P}<0.05$ vs. the group treated with $0 \mathrm{U} / \mathrm{ml}$ of IL-2; ${ }^{\#} \mathrm{P}<0.05 \mathrm{vs}$. the group treated with $100 \mathrm{U} / \mathrm{ml}$ of IL-2; ${ }^{\Delta} \mathrm{P}<0.05$ vs. the group treated with $300 \mathrm{U} / \mathrm{ml}$ of IL-2. FCM, flow cytometry; NK, natural killer; 7-AAD, 7-aminoactinomycin D; IL-2, interleukin-2; FSC, forward scatter; SSC, side scatter; FITC, fluorescein isothiocyanate; PE, phycoerythrin. 


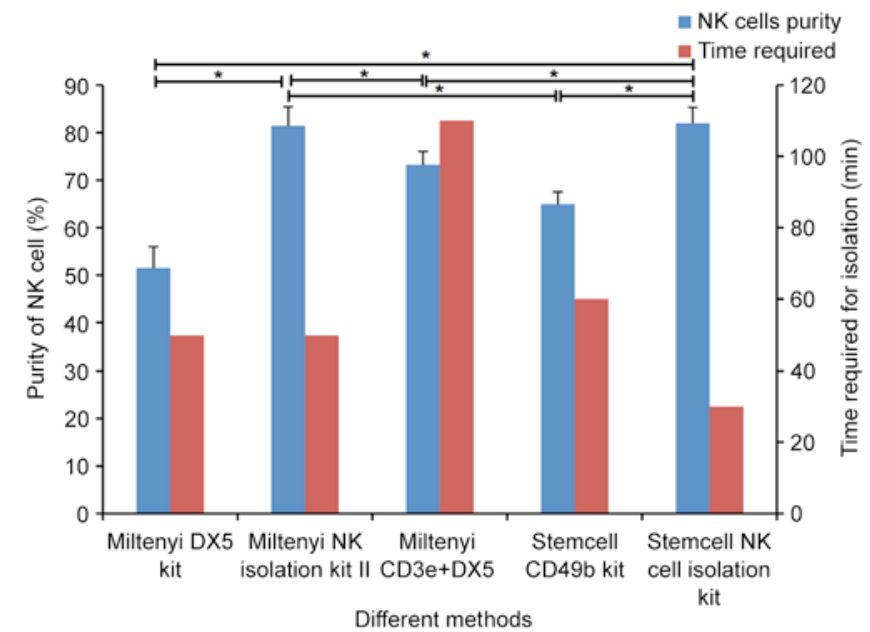

Figure 7. NK cell purity and the time required for isolation in different kits. The left Y-axis represents the NK cell purity obtained using the different methods. Data are expressed as mean \pm standard deviation. The right Y-axis represents the time required for purification, according to manufacturer's instructions of each respective kit. ${ }^{*} \mathrm{P}<0.05$. NK, natural killer; $\mathrm{CD}$, cluster of differentiation.

as combining this kit with the CD3-positive selection kit, which can remove all $\mathrm{CD}^{+}$cells, including NKT cells and therefore improve the purity of NK cells. Furthermore, it was identified with DX5-positive selection that the NK cell purity of isolates was variable based on the different markers used. The Stemcell CD49b Positive Selection kit is a typical representation. Following isolation, the purity of CD49b-positive cells was $>95 \%$ in the isolated cells, whereas the purity of $\mathrm{CD} 49 \mathrm{~b}^{+} \mathrm{CD} 3 \varepsilon^{-}$cells was $\sim 80 \%$ and the purity of $\mathrm{NK} 1.1^{+} \mathrm{CD} 3 \varepsilon^{-}$ cells was $\sim 65 \%$. The different purity of NK cells based on different markers was also associated with the expression of CD49b $(16,17)$. Therefore, when the purity of isolated NK cells was identified using the DX5-positive selection kit, the classic surface markers were revealed to be the preferential choice over other markers. Consequently, isolating NK cells using only the CD49b-positive strategy is not recommended; however, this kit provides improved results when combined with the CD3-positive selection kit.

Although combining the use of $\mathrm{CD} 3 \varepsilon$ positive selection with DX5 positive selection may improve the purity of NK cell, the time required for isolation was extended. Additionally, the NK cell is a functionally and phenotypically heterogeneous population (18) and perhaps only a specific subpopulation is isolated by positive selection. It has also been described that in vitro cultured NK cells are no longer recognized by DX5 antibodies (19). Moreover, DX5 is not expressed on immature NK cells and tissue-resident NK cells in the liver $(20,21)$. Therefore, the isolation of NK cells via CD49b as a positive selection marker should be undertaken depending on the experiment requirements. The negative selection of NK cells can capture naïve cells. It is critical that functional studies are performed in the future. There are several advantages of negative selection with one of these being that the NK cells are not coated with antibody and, therefore, are not at risk of functional perturbation by antibody cross-linking. Additionally, negative selection provides a way to isolate diverse subpopulations of NK cells without selectively purifying a specific subpopulation (13). In our comparative experiments, high purity and yield of NK cells were obtained in a shorter time frame using the negative selection method, particularly with the Stemcell Mouse NK Cell Isolation kit. The Miltenyi NK Cell Isolation kit II was also indicated to be a suitable choice of kit if the granulocytes of the spleen are depleted prior to sorting.

NK cells are short-lived and IL-2 dependent in vitro (22). IL-2 exposure; however, will result in differences owing to activation, such as NK cell killing of a broader panel of targets, which may be inappropriate for certain experimental settings. Therefore, a suitable concentration of IL-2 is critical for specific studies. In the present report, the NK cell purity and viability was compared with or without different concentrations of IL-2 $(0,100,300$ or $500 \mathrm{U} / \mathrm{ml})$, following culturing for 24,48 or $72 \mathrm{~h}$ using the Stemcell negative selection kit. Without IL-2, the purity of NK cells significantly decreased over time; however, with the addition of $100 \mathrm{U} / \mathrm{ml}$ IL-2, the NK cell purity may be maintained at $>80 \%$ after $72 \mathrm{~h}$. The purity increased with increased concentrations of IL-2 at the same time point, and with the same concentration of IL-2 the purity was approximately the same at different time points. Consequently, the purity of NK cells was able to meet the requirement of the experiment no matter what concentration of IL-2 was used. However, the IL-2 concentration was critical for the viability of NK cells at different time points. Only $20 \%$ of NK cells were viable following $24 \mathrm{~h}$ without IL-2, and after $72 \mathrm{~h} \sim 10 \%$ were viable. Therefore, if studies wish to use NK cells in vitro for $>24 \mathrm{~h}$, IL-2 is required. The viability of NK cells was increased with high concentrations of IL-2 at the same time point, particularly at 48 and $72 \mathrm{~h}$. At a concentration of 100 or $300 \mathrm{U} / \mathrm{ml}$ of IL-2, the viability of NK cell was increased at $72 \mathrm{~h}$ when compared with 48 h exposure. Notably, the viability of NK cells was similar at different time points with $500 \mathrm{U} / \mathrm{ml} \mathrm{IL-2,} \mathrm{which}$ may be explained by NK cell proliferation. High concentrations $(500 \mathrm{U} / \mathrm{ml})$ of IL-2 are able to activate more NK cells to proliferate, which results in a balance between death and proliferation of NK cells. Thus, at different time points, the viability of $\mathrm{NK}$ cells is similar. However, low concentrations (100 or $300 \mathrm{U} / \mathrm{ml}$ ) of IL-2 are not able to activate more NK cells to proliferate; therefore, if a study requires the use of $\mathrm{NK}$ cells in vitro for $24 \mathrm{~h}$, the concentration of $300 \mathrm{U} / \mathrm{ml}$ IL-2 is recommended, based on the present results. If a study requires the use of NK cells in vitro for 48 or $72 \mathrm{~h}$, a concentration of $500 \mathrm{U} / \mathrm{ml} \mathrm{IL}-2$ is recommended.

In conclusion, it is important to consider that different NK cell isolation kits affect the purity and yield of isolated NK cells. When isolating NK cells using Miltenyi kits, the spleen cells should be pretreated to deplete the granulocytes prior to sorting. Combined use of the CD3e selection kit with the DX5 selection kit is able to produce higher purity and yield of NK cells. We favor the use of the negative selection kit from Stemcell, which can produce naïve NK cells that may be further analyzed. The present study revealed that IL-2 is essential for the viability of NK cells in vitro. The present study concludes that a concentration of $300 \mathrm{U} / \mathrm{ml}$ of IL-2 is recommended for the culture NK cells in vitro for $24 \mathrm{~h}$ to obtain optimal resolution and $500 \mathrm{U} / \mathrm{ml}$ of IL-2 is suitable for NK cells in vitro for 48 or $72 \mathrm{~h}$. 


\section{Acknowledgments}

The present study was supported by Chinese National Natural Science Foundation (grant no. 81373162) and Nature Science of Foundation of Liaoning Province, China (grant no. 2012225016).

\section{References}

1. Jost S and Altfeld M: Control of human viral infections by natural killer cells. Annu Rev Immunol 31: 163-194, 2013.

2. Bär E, Whitney PG, Moor K, Reis e Sousa C and LeibundGut-Landmann S: IL-17 regulates systemic fungal immunity by controlling the functional competence of NK cells. Immunity 40: 117-127, 2014.

3. Zitvogel L, Galluzzi L, Smyth MJ and Kroemer G: Mechanism of action of conventional and targeted anticancer therapies: Reinstating immunosurveillance. Immunity 39: 74-88, 2013.

4. Tian Z, Gershwin ME and Zhang C: Regulatory NK cells in autoimmune disease. J Autoimmun 39: 206-215, 2012

5. Kim HS, Das A, Gross CC, Bryceson YT and Long EO: Synergistic signals for natural cytotoxicity are required to overcome inhibition by c-Cbl ubiquitin ligase. Immunity 32: 175-186, 2010.

6. Shi FD, Ljunggren HG, La Cava A and Van Kaer L: Organ-specific features of natural killer cells. Nat Rev Immunol 11: 658-671, 2011.

7. Carlyle JR, Mesci A, Ljutic B, Belanger S, Tai LH, Rousselle E, Troke AD, Proteau MF and Makrigiannis AP: Molecular and genetic basis for strain-dependent NK1.1 alloreactivity of mouse NK cells. J Immunol 176: 7511-7524, 2006.

8. Charbonnier LM, van Duivenvoorde LM, Apparailly F, Cantos C, Han WG, Noël D, Duperray C, Huizinga TW, Toes RE, Jorgensen C and Louis-Plence P: Immature dendritic cells suppress collagen-induced arthritis by in vivo expansion of CD49b+ regulatory T cells. J Immunol 177: 3806-3813, 2006.

9. Hackett J Jr, Tutt M, Lipscomb M, Bennett M, Koo G and Kumar V: Origin and differentiation of natural killer cells. II Functional and morphologic studies of purified NK-1.1+ cells. J Immunol 136: 3124-3131, 1986.

10. Ravnik SE, Gage S and Pollack SB: Self-generating density gradients of Percoll provide a simple and rapid method that consistently enriches natural killer cells. J Immunol Methods 110: $161-168,1988$
11. Patel MR and Linna TJ: Enrichment of mouse splenic natural killer cells using discontinuous polyvinylpyrrolidone silica (Percoll) gradients. Immunology 53: 721-729, 1984.

12. Meinhardt K, Kroeger I, Abendroth A, Müller S, Mackensen A and Ullrich E: Influence of NK cell magnetic bead isolation methods on phenotype and function of murine NK cells. J Immunol Methods 378: 1-10, 2012.

13. Pak-Wittel MA, Piersma SJ, Plougastel BF, Poursine-Laurent J and Yokoyama WM: Isolation of murine natural killer cells. Curr Protoc Immunol 105: 3.22.1-9, 2014

14. Davis ZB, Felices M, Verneris MR and Miller JS: Natural killer cell adoptive transfer therapy: Exploiting the first line of defense against cancer. Cancer J 21: 486-491, 2015.

15. Nowarski R, Gagliani N, Huber S and Flavell RA: Innate immune cells in inflammation and cancer. Cancer Immunol Res 1: 77-84, 2013.

16. Wang C, Liu X, Li Z, Chai Y, Jiang Y, Wang Q, Ji Y, Zhu Z, Wan Y, Yuan Z, et al: CD8 (+)NKT-like cells regulate the immune response by killing antigen-bearing DCs. Sci Rep 5: $14124,2015$.

17. Kaufman G, d'Ovidio R, Kaldawy A, Assy B, Ullmann Y, Etzioni A, Paus R and Gilhar A: An unexpected twist in alopecia areata pathogenesis: Are NK cells protective and CD49b+ T cells pathogenic? Exp Dermatol 19: e347-e349, 2010.

18. Meinhardt K, Kroeger I, Bauer R, Ganss F, Ovsiy I, Rothamer J, Büttner M, Atreya I, Waldner M, Bittrich M, et al: Identification and characterization of the specific murine NK cell subset supporting graft-versus-leukemia- and reducing graft-versus-host-effects. Oncoimmunology 4: e981483, 2015

19. Arase H, Saito T, Phillips JH and Lanier LL: Cutting edge: The mouse NK cell-associated antigen recognized by DX 5 monoclonal antibody is CD49b (alpha 2 integrin, very late antigen-2). J Immunol 167: 1141-1144, 2001

20. Kim S, Iizuka K, Kang HS, Dokun A, French AR, Greco S and Yokoyama WM: In vivo developmental stages in murine natural killer cell maturation. Nature immunology 3: 523-528, 2002.

21. Peng H, Jiang X, Chen Y, Sojka DK, Wei H, Gao X, Sun R, Yokoyama WM and Tian Z: Liver-resident NK cells confer adaptive immunity in skin-contact inflammation. J Clin Invest 123: 1444-1456, 2013

22. Kuribayashi K, Gillis S, Kern DE and Henney CS: Murine NK cell cultures: Effects of interleukin-2 and interferon on cell growth and cytotoxic reactivity. J Immunol 126: 2321-2327, 1981. 